\title{
Water Origins over Central and Southern Japan during the Early Summer Rainy Season as Simulated with an Isotope Circulation Model
}

\author{
Ai Hiraoka ${ }^{1}$, Ryuichi Kawamura ${ }^{1}$, Kimpei Ichiyanagi ${ }^{2}$, Masahiro Tanoue ${ }^{2}$, and Kei Yoshimura ${ }^{3}$ \\ ${ }^{1}$ Graduate School of Science and Engineering, University of Toyama, Toyama, Japan \\ ${ }^{2}$ Graduate School of Science and Technology, Kumamoto University, Kumamoto, Japan \\ ${ }^{3}$ Atmosphere and Ocean Research Institute, The University of Tokyo, Tokyo, Japan
}

\begin{abstract}
By applying the Japanese long-term Re-Analysis project (JRA-25) and the Japan Meteorological Agency Climate Data Assimilation System (JCDAS) data to a Rayleigh-type global one-layer isotope circulation model, we performed a long-term simulation and examined how water vapor is remotely transported to the vicinity of Japan from water source regions during the early summer rainy (Baiu) season. We validated the model outputs, comparing them with the stable hydrogen and oxygen isotope ratios $\left(\delta \mathrm{D}\right.$ and $\left.\delta^{18} \mathrm{O}\right)$ of precipitation observed at two in situ sites in southern and central Japan during the 2010 Baiu, and determined that the correlations between the simulation and observation are comparable to those in precipitation in Thailand from August to October when the Asian summer monsoon withdraws. The model results demonstrate that the Baiu is characterized by relatively low values of $\delta \mathrm{D}$ and that the $\delta \mathrm{D}$ values over central Japan are lower than those over southern Japan. When the Baiu commences, Indian Ocean water increases rapidly and then contributes substantially to the total precipitable water until the withdrawal of the Baiu, which is partially responsible for the low values of $\delta \mathrm{D}$. Once the Baiu withdraws, alternatively, Pacific Ocean water occupies most of the total precipitable water. Another signature of its withdrawal is the decrease in land water of the Eurasian continent. It is also clear that the intrusion of the Indian Ocean water into central Japan remained until the end of August in the extremely cool summers of 1993 and 2003, which is interpreted as an extraordinary persistence of the Baiu period.
\end{abstract}

\section{Introduction}

As introduced in Kawamura and Murakami (1998), the Baiu (in Japanese) or Meiyu (in Chinese) has a midlatitude frontal character combined with a tropical convective nature. Flohn and Oeckel (1956) first noted that large amounts of moisture are transported by low-level monsoonal southwesterlies from the Bay of Bengal to Japan. Another large-scale moisture transport along the western periphery of the Pacific high also becomes pronounced, particularly at the later stage of the Baiu (e.g., Murakami 1959). These changes in the large-scale moisture transport characterize the time evolution and activity of the Baiu. Despite the significant amount of literature on the Baiu and Meiyu, few studies have highlighted the large-scale moisture transport in terms of the isotopic variability in precipitation because the daily variability in the isotopic composition of precipitation was less reliable.

It is well known that the stable isotopes in precipitation undergo spatial and temporal changes through both atmospheric transport processes and complicated condensation and evaporation processes (e.g., Dansgaard 1964). Recently, Yoshimura et al. (2003, 2004b) demonstrated that large-scale moisture transport regulates the isotopic variability in precipitation at daily time scales because

Corresponding author: Ryuichi Kawamura, University of Toyama, 3190 Gofuku, Toyama 930-8555, Japan. E-mail: kawamura@sci.u-toyama.ac.jp. (C)2011, the Meteorological Society of Japan. their isotopic circulation model was successful in reproducing isotopic signals in precipitation even though the "well-mixed" assumption that water vapor is completely mixed in each grid for every time step was adopted in the model. Subsequently, Yoshimura et al. (2004a) and Ichiyanagi et al. (2005) demonstrated that the model is very useful to explain the monsoon transition in the Asian monsoon regions where convective precipitation is predominant. Fudeyasu et al. (2011) also confirmed that their model is capable of reproducing observed isotopic changes with intraseasonal time scales at Sumatera, Indonesia. However, how the transition of the East Asian summer monsoon is characterized by large-scale moisture transport using such a model has not yet been addressed. Thus, the purpose of this study is to examine how water vapor that is remotely transported into the vicinity of Japan from water source regions varies during the early summer rainy (Baiu) season in Japan and to further explain the onset and withdrawal of the Baiu season in terms of water origins.

\section{Data used and analysis procedures}

Using a mass spectrometer (Thermo Quest, Delta S) at Kumamoto University, we measured the stable hydrogen and oxygen isotope ratios ( $\delta \mathrm{D}$ and $\left.\delta^{18} \mathrm{O}\right)$ of the precipitation observed at Ishigaki-jima $\left(124.2^{\circ} \mathrm{E}, 24.4^{\circ} \mathrm{N}\right)$ in the Ryukyu Islands from 1 May to 31 August 2010 and at Toyama $\left(137.7^{\circ} \mathrm{E}, 36.7^{\circ} \mathrm{N}\right)$ in central Japan from 16 June to 30 September 2010. The analytical errors of the instrument used are less than \pm 1 per mil for $\delta \mathrm{D}$ and \pm 0.1 per mil for $\delta^{18} \mathrm{O}$. Because Ishigaki-jima and Toyama are located in southern and central Japan, respectively, these two in situ observation sites are useful to clarify the behavior of the early summer rainy season at its early and mature stages also. We consider that Ishigaki-jima and Toyama are also appropriate sites in that they are representative regions reflecting the low- and midlatitude characteristics of the Baiu, respectively.

A Rayleigh-type global one-layer isotope circulation model (ICM) developed by Yoshimura et al. (2003) is utilized to simulate the isotope composition of precipitation. Atmospheric water circulation calculations maintain the atmospheric water balance (Oki et al. 1995) by an upstream scheme in each grid for every 10-minute time step. A colored moisture analysis (CMA) based on the ICM (Yoshimura et al. 2004a) is applied to track the water origins. In this study, the globe is divided into 56 tagged-water source regions. Figure 1 reveals the partition of the main taggedwater source regions considered in this study. Note that the vicinity of the western North Pacific region is finely partitioned because we highlight the large-scale moisture transport into the Baiu front. The model incorporates an external meteorological dataset derived from the Japanese Long-term Reanalysis project (JRA-25) (Onogi et al. 2007) with a spatial resolution of $1.25^{\circ}$ longitude by $1.25^{\circ}$ latitude for the period of 1979-2004 as well as data from the Japan Meteorological Agency (JMA) Climate Data Assimilation System (JCDAS) with the same resolution for the period of 2005-2010. The 6-hourly precipitable water, vertically integrated moisture fluxes, precipitation, and evaporation data are used to calculate the atmospheric water balance.

Table 1 shows the validation of the $\delta \mathrm{D}$ and $\delta^{18} \mathrm{O}$ in precipita- 


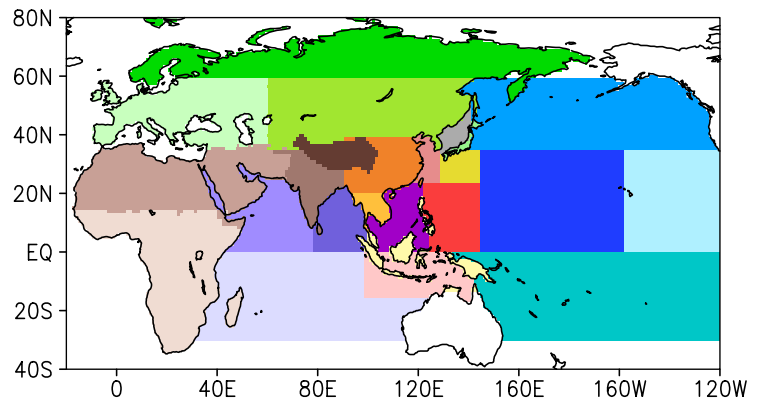

Fig. 1. Partition of tagged-water source regions. Different colors denote different origins.

tion at Ishigaki-jima and Toyama. The correlations at Ishigakijima tend to be higher than those at Toyama, but all correlation coefficients satisfy a $1 \%$ level of statistical significance. Conversely, the RMS errors at Toyama are smaller than those at Ishigakijima. The reliability of the analysis is comparable to the results of Ichiyanagi et al. (2005), who validated the $\delta^{18} \mathrm{O}$ in precipitation in Thailand, although the simulated $\delta \mathrm{D}$ and $\delta^{18} \mathrm{O}$ are underestimated (see also their Fig. 2). Similar results might have been obtained because the Baiu front is also largely characterized by convective precipitation. In this study, we present the values of simulated $\delta \mathrm{D}$ between the two different isotope ratios in the next section because the cross-correlations in $\delta \mathrm{D}$ between the observed and simulated values are higher than those in $\delta^{18} \mathrm{O}$.

\section{Results}

\subsection{Simulated water origins at Ishigaki-jima and Toyama in 2010}

Figure 2 shows the daily variations in the water origins of total precipitable water and $\delta \mathrm{D}$ at Ishigaki-jima in the Ryukyu Islands during the period from 1 May to 31 July 2010, along with the daily rainfall variations observed. According to JMA, the onset and withdrawal dates of the Baiu in 2010 in the Ryukyu Islands are around May 6 and June 19, respectively. Nearly concurrent with the onset date, Indian Ocean water commences to increase and then contributes substantially to the total precipitable water until the withdrawal of the Baiu, although its variability is large during the Baiu period. Note here that the Indian Ocean consists of three sectors: the Bay of Bengal, the Arabian Sea, and the southern Indian Ocean. Land water from China also contributes to the total precipitable water during the same period. Once the Baiu withdraws, however, the water is abruptly replaced by Pacific Ocean water. The tendency of $\delta \mathrm{D}$ is roughly uniform from May through July, except for its decrease when the Indian Ocean water increases.

In a similar fashion, Fig. 3 demonstrates the daily variations in water origins of total precipitable water and $\delta \mathrm{D}$ at Toyama in central Japan from 1 June to 31 August 2010. The JMA reports that the onset and withdrawal dates of the Baiu at Toyama are around June 13 and July 17, respectively. Indian Ocean water appears around the onset date and disappears just after the withdrawal date. Land water of the continent also dissipates around the withdrawal date and, alternatively, Pacific Ocean water occupies most of the total precipitable water after the withdrawal of the Baiu. These features are basically common between the two observation sites. On the other hand, one of the largest differences between the two sites is the daily variations in $\delta \mathrm{D}$. It turns out that, at Toyama,
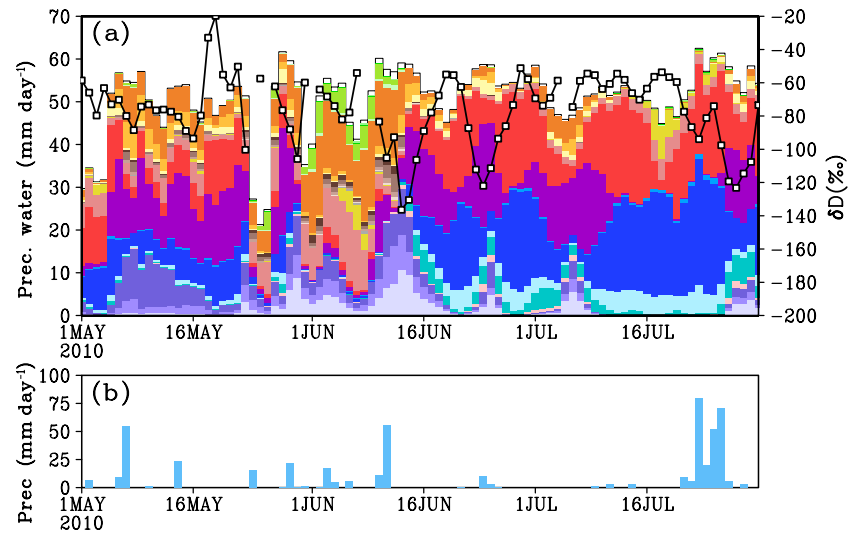

Fig. 2. (a) Daily variations in the water origins (color bar) of total precipitable water and $\delta \mathrm{D}$ (solid line) at Ishigaki-jima in the Ryukyu Islands of Japan during the period from 1 May to 31 July 2010. Different color shadings denote the variations in the different water origins shown in Fig. 1. (b) Daily rainfall variations observed at Ishigaki-jima.

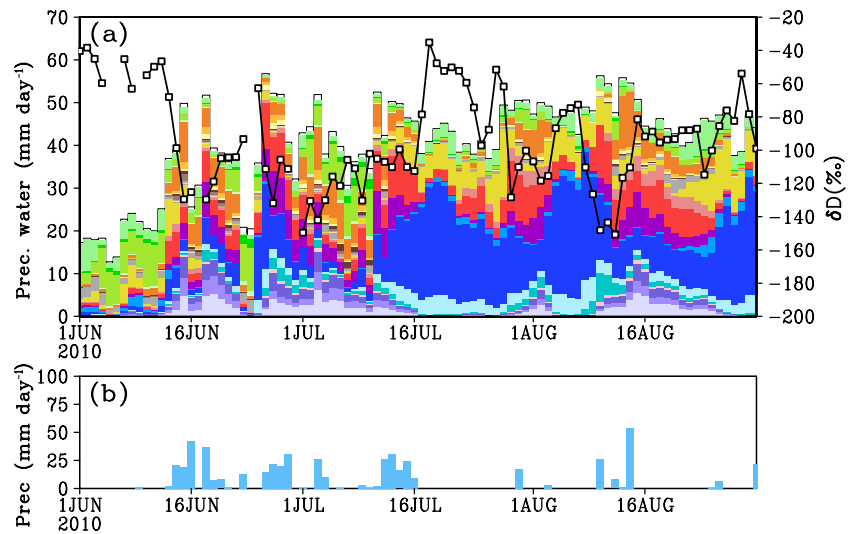

Fig. 3. As in Fig. 2 but for Toyama in central Japan during the period from 1 June to 31 August 2010.

the $\delta \mathrm{D}$ decreases and increases rapidly at the Baiu onset and withdrawal, respectively, which is different from the case at Ishigakijima. In the next subsection, we present the climatological features of large-scale moisture transport over southern and central Japan during boreal early and middle summer in terms of the water origins and $\delta \mathrm{D}$ variability to confirm whether the 2010 case has general features.

\subsection{Climatological features of water origins during the Baiu period}

To understand the overall features of the major water origins, we focused specifically on four major water source regions: the Eurasian continent (Central Eurasia and China), the Indian Ocean (the Bay of Bengal, the Arabian Sea, and the southern Indian Ocean), the western North Pacific (the South China Sea, the Philippine Sea, and the Kuroshio Current region), and the central North Pacific Ocean.

Figure 4 shows the climatological five-day (pentad) mean variations in the selected water origins of total precipitable water and $\delta \mathrm{D}$ at Ishigaki-jima in southern Japan during the period from

Table 1. Validations of simulated $\delta \mathrm{D}$ and $\delta^{18} \mathrm{O}$ in precipitation at Ishigaki-jima in southern Japan and Toyama in central Japan. Note that single asterisk denotes the correlation coefficient with the $1 \%$ level of statistical significance.

\begin{tabular}{lcccccc}
\hline Observation site & Observation period & Sampling days & Correlation $(\delta \mathrm{D})$ & RMSE $(\delta \mathrm{D})$ & Correlation $\left(\delta^{18} \mathrm{O}\right)$ & $\mathrm{RMSE}\left(\delta^{18} \mathrm{O}\right)$ \\
\hline Ishigaki jima & $5 / 1-8 / 31 / 2010$ & 18 & $0.68^{*}$ & 15.81 & $0.66^{*}$ & 2.02 \\
Toyama & $6 / 16-9 / 30 / 2010$ & 47 & $0.58^{*}$ & 7.88 & $0.53^{*}$ & 1.10 \\
\hline
\end{tabular}



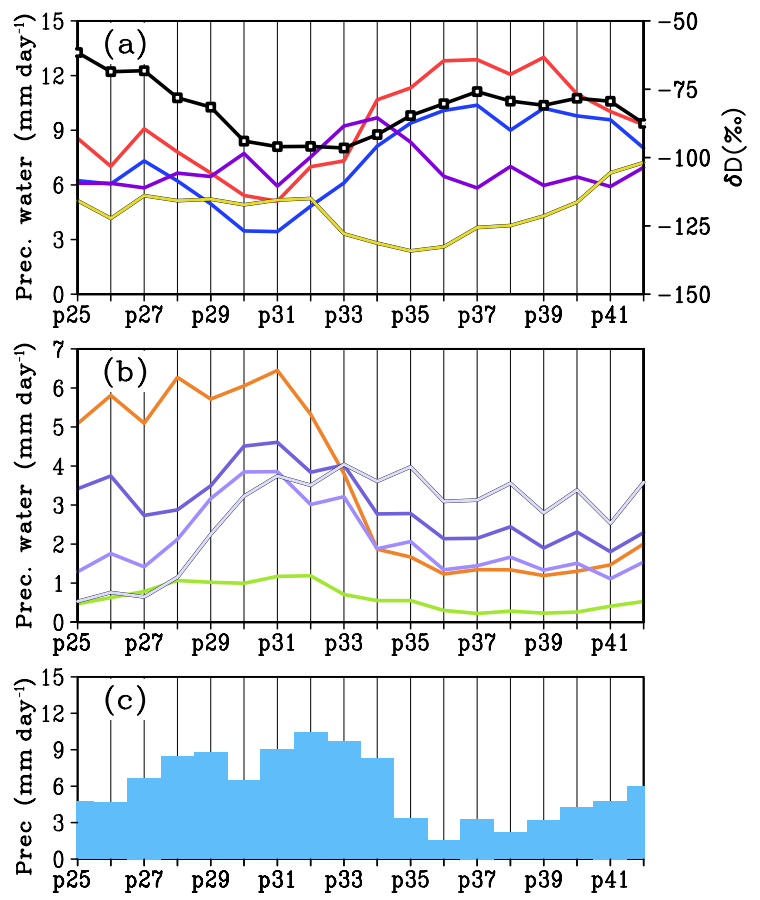

Fig. 4. (a) Climatological variations in the Pacific Ocean water origins (color lines) of total precipitable water and $\delta \mathrm{D}$ (black line) at Ishigakijima in the Ryukyu Islands during the period from Pentad 25 (May 1-5) to Pentad 42 (July 25-29). Different color lines denote the variations in the different water origins shown in Fig. 1. (b) As in (a) but for the Indian Ocean and the Eurasian continent water origins. (c) Climatology of rainfall variations observed at Ishigaki-jima.

early May to late July, based on the climatology of 1979-2010. From May to June, the Indian Ocean water increases accompanied by enhanced precipitation. In terms of precipitation, the Baiu withdrawal pentad is around Pentad 35 (June 20-24), but the decreases in the Bay of Bengal and the Arabian Sea water can already be seen from Pentad 33 (June 10-14) to Pentad 34 (June 15 -19). Land water of China region also decreases drastically during the same period. Alternatively, the Philippine Sea and the central North Pacific water tend to increase after Pentad 33 and persist until late July. Judging from the changes in the water origins, the withdrawal pentad at Ishigaki-jima is Pentad 34 in climate terms, but the onset pentad is vague. Although the $\delta \mathrm{D}$ change at Ishigakijima was not evident before and after the Baiu period of 2010 (Fig. $2)$, the $\delta \mathrm{D}$ values are climatologically low during the Baiu period.

Figure 5 reveals the climatological pentad mean variations in the selected water origins of total precipitable water and $\delta \mathrm{D}$ at Toyama as well as Ishigaki-jima. According to Kawamura and Murakami (1998), who examined the climatological features of the Baiu in terms of the large-scale circulations, the Baiu onset and withdrawal pentads correspond to Pentad 33 and Pentad 41 (July 20-24), respectively. The decrease in $\delta \mathrm{D}$ at Toyama occurs during the Baiu period, although, in climate terms, the rapid changes of $\delta \mathrm{D}$ at the onset and the withdrawal phase are not very apparent. The increases in the Bay of Bengal, the Arabian Sea, and the Southern Indian Ocean water during the Baiu period are commonly simulated, which is similar to the case of 2010 . The Indian Ocean water decreases rapidly from Pentad 41 to Pentad 42. The time evolution of the South China Sea water is also similar to that of the Indian Ocean water. In contrast, the Philippine Sea water and the Kuroshio Current region water tend to gradually increase during the Baiu period, reach their peaks around the withdrawal phase, and persist until August. It is interesting to note that the rapid increase of the central North Pacific water from Pentad 41 to Pentad 42 is more evident than that of the other region's water. Likewise, land water of the Eurasian continent, especially China, tends to decrease at the same pentad.
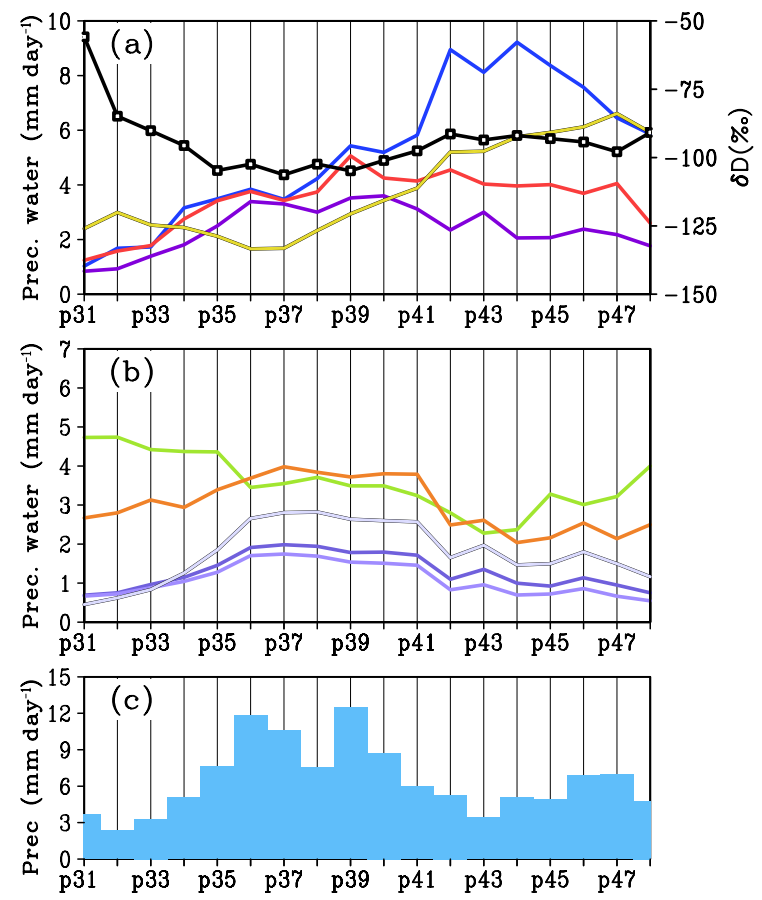

Fig. 5. As in Fig. 4 but for Toyama in central Japan during the period from Pentad 31 (May 31-June 4) to Pentad 48 (August 24-28).

The results above indicate that the increases of the Indian Ocean water and the South China Sea water are one of the main signatures of the Baiu onset in central Japan and that the replacement of the Indian Ocean water by the Pacific Ocean water represents the withdrawal of the Baiu. As for Toyama, the most appropriate pentad identified with the withdrawal may be Pentad 42 rather than Pentad 41 because both the relatively rapid decrease of the Indian Ocean and the rapid increase of the central North Pacific Ocean water occur from Pentad 41 to Pentad 42.

The precipitable water amount of each water origin is considerably different between the two sites during boreal early and middle summer. For instance, at Ishigaki-jima, the Philippine Sea water exceeds $10 \mathrm{~mm}$ after the withdrawal of the Baiu, but, at Toyama, its value is less than $5 \mathrm{~mm}$. The difference in the South China Sea water amount is also large between the two. Likewise, the change in the China region water amount around the withdrawal phase at Ishigaki-jima is about four times as large as that at Toyama. An explanation for the significant reductions and increases in the $\delta \mathrm{D}$ with the Baiu onset and withdrawal needs to be presented. The change in $\delta \mathrm{D}$ is very significantly correlated with that of the Indian Ocean water at both sites. When the Indian Ocean water is remotely transported and reaches the southern and central Japan, its $\delta \mathrm{D}$ is, in fact, considerably lower than that in the other regions. Since the Indian Ocean water is transported by the Asian monsoon flow on a continental scale, we anticipate that, in the meantime, its $\delta \mathrm{D}$ becomes low through active rain-out processes, which is also consistent with the fact that the $\delta \mathrm{D}$ values at Toyama in central Japan are lower than those at Ishigaki-jima in the Ryukyu Islands.

\subsection{Changes in the water origins in extreme summers}

Japan experienced an extremely hot summer in 2010. As shown in Fig. 3, once the Baiu withdraws, the Pacific Ocean water becomes predominant, accompanied by the westward extension of the North Pacific high toward Japan. Such features can also be seen in other hot summers (figure not shown). On the contrary, the changes in water origins in extraordinary cool summers are considerably different from those in hot summers.

Figure 6 shows the daily variations in the water origins of total precipitable water and $\delta \mathrm{D}$ at Toyama in central Japan in the exceptionally cool summers of 1993 and 2003. It is noteworthy that no 

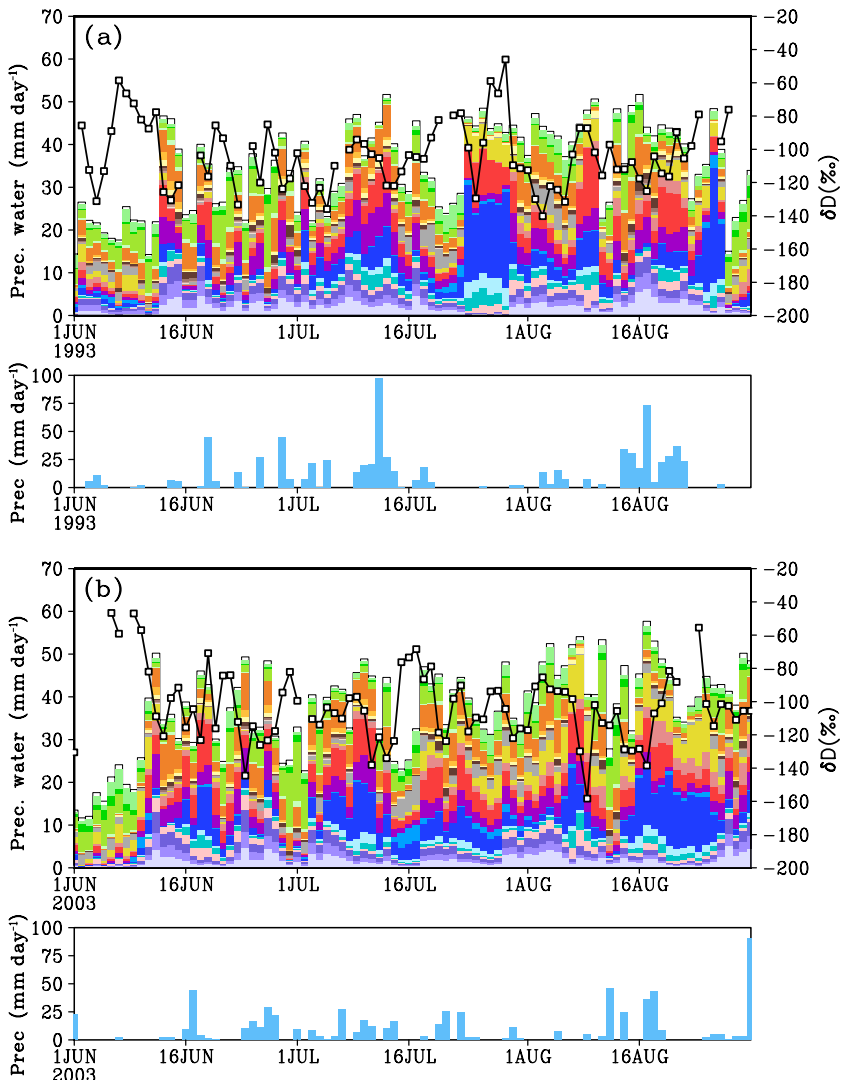

Fig. 6. Daily variations in the water origins of total precipitable water and $\delta \mathrm{D}$ at Toyama in central Japan in exceptionally cool summers of (a) 1993 and (b) 2003.

obvious withdrawal of the Baiu occurs in both summers. One of the notable features is that the intrusion of the Indian Ocean water, which is a salient signature of the Baiu onset, persists until the end of August. The amount of the Pacific Ocean water has a short-term periodic nature and is not pronounced during midsummer, despite its dominance is a signature of the Baiu withdrawal. Other water origins also tend to fluctuate frequently during almost the same period. These features indicate that the severe cool summers are characterized by the extraordinary persistence of the Baiu period. In particular, it turns out that the persistence of the Indian Ocean water during midsummer is more evident than it is in the other water origins.

\section{Summary}

To clarify the overall features of the changes in the water origins over central and southern Japan during the early summer rainy (Baiu) season, we conducted long-term simulations of an isotopic circulation model using the JRA-25 and JCDAS data and tried to track the water origins on the basis of a colored moisture analysis. The in situ precipitation observations at Ishigaki-jima and Toyama, which are representative stations in southern and central Japan, respectively, demonstrate that the accuracy of simulated $\delta \mathrm{D}$ and $\delta^{18} \mathrm{O}$ in precipitation is comparable to that in precipitation in Thailand from August to October (Ichiyanagi et al. 2005). Nearly concurrent with the Baiu onset, the increase in the Indian Ocean water is evident at both observation sites, whereas the Pacific Ocean water alternatively prevails after the withdrawal of the Baiu. Its withdrawal is also characterized by the decrease in the Eurasian continent water. Associated with these changes in the water origins, the values of $\delta \mathrm{D}$ tend to be low during the Baiu period. The increase in the Indian Ocean water is partially responsible for such decreases of $\delta \mathrm{D}$ because the $\delta \mathrm{D}$ of the Indian
Ocean water becomes low through rain-out processes as it is remotely transported by the Asian monsoon flow. It is found that the Baiu period can be characterized by the behaviors of both $\delta \mathrm{D}$ in precipitation and water origins. In the severely cool summers of 1993 and 2003, the intrusion of the Indian Ocean water into central Japan is maintained until the end of August, suggesting the extraordinary persistence of the Baiu period.

Although we analyzed the $\delta \mathrm{D}$ and $\delta^{18} \mathrm{O}$ in precipitation observed at Ishigaki-jima and Toyama during the Baiu period of 2010 to validate the applicability of a Rayleigh-type global none-layer isotope circulation model developed by Yoshimura et al. (2003), we are certainly aware that both longer-term in situ precipitation data and more observation sites should be required to clarify the detailed features of the large-scale moisture transport in the vicinity of the East Asian monsoon regions. Collecting various observation data concerning stable isotope ratios of precipitation, further intensive studies on the issues above are expected to be conducted in the near future.

\section{Acknowledgments}

The authors thank Dr. Kiyoshi Ozawa of JIRCAS for observing precipitation at Ishigaki-jima. Comments by the editor, two anonymous reviewers were extremely helpful. This research was supported by JSPS KAKENHI (22310111) and MEXT KAKENHI (22106005).

\section{References}

Dansgaard, W., 1964: Stable isotopes in precipitation. Tellus, 16, 436-468.

Flohn, H., and H. Oeckel, 1956: Water vapor flux during the summer rains over Japan and Korea. Geophys. Mag., 27, $527-532$.

Fudeyasu, H., K. Ichiyanagi, K. Yoshimura, S. Mori, J.-I. Hamada, N. Sakurai, M. D. Yamanaka, J. Matsumoto, and F. Syamsudin, 2011: Effects of large-scale moisture transport and mesoscale processes on precipitation isotope ratios observed at Sumatera, Indonesia. J. Meteor. Soc. Japan, 89A, 49-59.

Ichiyanagi, K., K. Yoshimura, and M. D. Yamanaka, 2005: Validation of changing water origins over Indochina during the withdrawal of the Asian monsoon using stable isotopes. SOLA, 1, 113-116.

Kawamura, R., and T. Murakami, 1998: Baiu near Japan and its relation to summer monsoons over Southeast Asia and the western North Pacific. J. Meteor. Soc. Japan, 76, 619-639.

Murakami, T., 1959: The general circulation and water vapor balance over the Far East during the rainy season. Geophys. Mag., 29, 131-171.

Oki, T., K. Musiake, H. Matsuyama, and K. Masuda, 1995: Global atmospheric water balance and runoff from large river basins. Hydrol. Process., 9, 655-678.

Onogi, K., J. Tsutsui, H. Koide, M. Sakamoto, S. Kobayashi, H. Hatsushika, T. Matsumoto, N. Yamazaki, H. Kamahori, K. Takahashi, S. Kadokura, K. Wada, K. Kato, R. Oyama, T. Ose, N. Mannoji, and R. Taira, 2007: The JRA-25 reanalysis. J. Meteor. Soc. Japan, 85, 369-432.

Yoshimua, K., T. Oki, N. Ohte, and S. Kanae, 2003: A quantitative analysis of short-term ${ }^{18} \mathrm{O}$ variability with a Rayleigh-type isotope circulation model. J. Geophys. Res., 108(D20), 4647, doi:10.1029/2003JD003477.

Yoshimua, K., T. Oki, N. Ohte, and S. Kanae, 2004a: Colored moisture analysis estimates of variations in 1998 Asian monsoon water sources. J. Meteor. Soc. Japan, 82, 1315-1329.

Yoshimua, K., T. Oki, and K. Ichiyanagi, 2004b: Evaluation of two-dimensional atmospheric water circulation fields in reanalyses by using precipitation isotopes databases. J. Geophys. Res., 109, D20109, doi:10.1029/2004JD004764.

Manuscript received 24 June 2011, accepted 4 September 2011

SOLA: http://www.jstage.jst.go.jp/browse/sola 